И. С. Болдонова, Чжао Чуньмэй. Герменевтический аспект интерпретации буддийских текстов методом гэ $u$

УДК 1:294.3

DOI: 10.18101/1994-0866-2020-2-28-36

\title{
ГЕРМЕНЕВТИЧЕСКИЙ АСПЕКТ ИНТЕРПРЕТАЦИИ БУДДИЙСКИХ ТЕКСТОВ МЕТОДОМ ГЭ И
}

\author{
(c) Болдонова Ирина Сергеевна \\ доктор философских наук, доцент, \\ приглашенный профессор кафедры русского языка Нанькайского университета \\ (Китай), профессор кафедры русской и зарубежной литературы, \\ Бурятский государственный университет имени Доржи Банзарова \\ Россия, 670000, г. Улан-Удэ, ул. Смолина, 24а \\ E-mail: irina_duncan@mail.ru \\ (c) Чжао Чуньмэй \\ Ph.D., доцент кафедры русского языка Нанькайского университета, \\ Нанькайский университет, Институт иностранных языков \\ Китай, 300371, г. Тяньцзинь, ул. Вэйцзиньлу, 94 \\ E-mail: 1559614118@qq.com
}

\begin{abstract}
В статье рассматривается метод гэ $u$, которым пользовались даосские монахи при переводе буддийских сутр во время распространения буддизма из Индии в Китай. Авторы статьи подчеркивают культурно-историческую роль метода гэ $u$ на раннем этапе проникновения индийского буддизма в Китай и его специфическую природу интерпретации путем подбора и замены аналогичными терминами и понятиями китайской философии. Авторы рассматривают герменевтический аспект метода гэ $и$ через такие категории, как сознание интерпретатора, процесс познания, культурно-историческая традиция, межкультурная коммуникация, аппликация и проблема понимания. В статье также говорится о некотором сравнении процесса интерпретации в методе $ә э и \mathrm{c}$ таковым в буддийской герменевтике, что помогло авторам дополнительно выявить особенности герменевтического аспекта метода гэ и. Оба метода каждый по-своему решает проблемы истинности знаний, понимания и интерпретации священных текстов. В заключении авторы приходят к выводу об эвристической значимости метода гэ $u$, его роли в развитии межкультурной коммуникации.

Ключевые слова: метод гэ $u$; буддизм; китайская философиям герменевтический аспект; буддийские тексты; даосские монахи-переводчики; интерпретация; понимание; культурно-историческая традиция; буддийская герменевтика.
\end{abstract}

\section{Для цитирования}

Болдонова И. С., Чжсао Чуньмэй. Герменевтический аспект интерпретации буддийских текстов методом гэ и // Вестник Бурятского государственного университета. Философия. 2020. Вып. 2. С. 28-36.

В Древнем Китае ко II в. сложились общественно-исторические, политические, экономические и культурные предпосылки к восприятию идей буддизма. В самом китайском обществе того времени религиозные идеи носили форму высокой степени философской рефлексии над космосом, миром и обществом, в котором живет человек. На протяжении многовековой истории религиозные верова- 
ния продолжали играть большую роль в процессе развития духовной и материальной культуры, самосознания и формирования единого основания китайской нации, становления и совершенствования самобытной китайской цивилизации.

До проникновения буддизма из Индии в Древнем Китае существовали конфуцианство и даосизм как два главных направления философских и религиозных исканий китайских мудрецов. На момент знакомства с буддизмом китайское общество достигло достаточно высокого уровня культурного развития и вступило в эпоху межкультурных контактов, впервые оказавшись перед лицом нового, неизведанного, которое шло вместе с буддизмом из Индии. Распространение буддизма не встретило какого-либо значительного сопротивления со стороны знати, верующих, последователей даосизма и конфуцианства, что благоприятно сказалось на дальнейшем процессе успешной адаптации в китайской среде. Более того, буддизм оригинальным способом дополнил местные учения идеями достижения нравственного совершенства, снискал доверие и приобрел большое количество адептов.

Новое учение должно было найти путь к умам и сердцам китайцев через переводы буддийских текстов. В научной литературе по теме проникновения и распространения буддизма в Китае написано много о проблемах перевода с санскрита на китайский язык, о сложностях перевода и толкования терминологии. Для перевода буддийских сутр использовали метод гэ $u$. Понятие «гэ и» впервые появляется в Гао сэн чжуань (高僧傳), или «Жизнеописании достойных монахов», что является памятником буддийской исторической литературы, составленным Хуйцзяо (кон. V-VI вв.).

О. И. Костикова и Чэнь Шуи считают, что первым переводчиком и изобретателем гэ $u$ был иностранный монах: «В 148 г. Ань Шигао прибыл в Лоян (洛阳), столицу Восточной Хань, и начал переводить с санскрита на китайский язык буддийские сутры. На протяжении 20 лет, с 148 по 172 год, он перевел 35 томов и 41 свиток буддийских сутр, в том числе "Мин-ду-у-ши-цзяо-цзи Цзин" (明度五 十校计经), "Анапанасати сутру" (安般守意经, кит. Ань-шоу-и Цзин) и др. Он положил начало принципу перевода - "гэ и" ("согласование смыслов", "выверение смысла" терминов по имеющимся образцам) для наиболее адекватной передачи смысла оригинала» [2, с. 35].

Гэ $u$ (格义) представляет собой метод аналогии и принадлежит к понятийнокатегориальному аппарату китайской философии. Первый иероглиф гэ (格) обозначает сравнение и измерение, второй иероглиф $u(\mathcal{X})$ - название, объект или понятие. Гэ $u$ - это метод, интерпретирующий и излагающий понятия двух культур посредством сравнения и аналогии. Понятие гэ $u$ имеет широкое и узкое значения. Гэ $u$ в широком значении представляет собой метод аналогии всестороннего рассмотрения и посредством сравнения на межкультурном фоне поиск схожих по смыслу и содержанию понятий. Исторически было принято считать, что гэ $u$ соединяет мысли, используя фон межкультурного диалога [5].

Первое упоминание использования гэ $u$ в узком значении приходится на эпоху переводов и дальнейшего синтеза индийского буддизма с китайским даосизмом и конфуцианством. В период проникновения буддизма из Индии в Китай метод гэ $u$ первоначально использовался в узком значении для перевода сутр, но 
И. С. Болдонова, Чжао Чуньмэй. Герменевтический аспект интерпретации буддийских текстов методом гэ $u$

по мере распространения буддийской книжной учености гэ $u$ выполняет первичную функцию передачи мыслей иной веры, а вместе с тем и некоторых знаний о другой культуре.

В книге Чжао лунь Сэнчжао в период Восточного Цзинь говорится о совершенствовании гэ $u$ в Китае. Чэнь Янькэ является первым автором, который подробно излагает принципы гэ $и$. Известный китайский ученый Фэн Юлань изучал источники о гэ $u$, считая его методом изложения современных явлений древними понятиями и названиями, изложения китайских названий западными. За ним появились ученые Тан Юнтон, Фэн Юлань и другие [6].

$\mathrm{C}$ начала новой истории ученые стали обращать большое внимание на гэ $u$, западные мысли гораздо чаще стали проникать в Китай, и от этого проблем в межкультурной коммуникации становилось все больше и больше. По мнению ученого Фэн Юлань, гэ $u$ представляет собой необходимое явление и нужный метод на стадии начальной встречи двух культур. Фэн Юлань пишет: «B III-IV вв. на китайский язык были переведены многие буддийские тексты более метафизического характера, что способствовало лучшему пониманию буддизма. В это время к буддизму уже относились так же, как и к философскому даосизму (в лице Чжуан-цзы), а не как к религии даосов. Часто буддийские сочинения интерпретировались на основе философских идей даосизма. Подобный метод назывался гэ $u$, "толкованием по аналогии"» [7].

Естественно, что такой метод вел к наложениям и неточностям. Поэтому к V в., когда переводы хлынули потоком, от него отказались. Тем не менее остается фактом, что крупнейшие буддийские авторы $V$ в., не исключая даже индийского* учителя Кумарадживы, продолжали использовать для выражения буддийских концепций такие даосские понятия, как то (наличие, существующее), $y$ (отсутствие, несуществующее), ю вэй (деяние) и у вэй (недеяние). Различие же между этим методом и «толкованием по аналогии» заключается в том, что если в последнем видят лишь поверхностное сходство слов, то в первом - внутреннюю связь выражаемых ими идей. Поэтому такая практика не только не представляла собой искажения или непонимания буддизма, но, как мы увидим, способствовала синтезу индийского буддизма и даосизма, что привело к формированию собственно китайского буддизма» [7, с. 264-265].

Стоит заметить, что вместе с попытками первых переводчиков и толкователей в Китае понять священные тексты буддизма и иную культуру, возникает герменевтический аспект перевода или по-другому проблемы понимания и интерпретации буддийских сутр.

Метод гэ $u$ по-своему решает и проблему понимания, и проблему интерпретации. В этот процесс включался вопрос не только взаимодействия текста и интерпретатора, но и сложный этап осмысления содержания текста и его возможных путей перевода. Здесь и возникает проблема личностного истолкования, переводческого видения и способности извлечения новой информации для верующих и новых последователей буддизма. Первые переводчики воспринимали буддийские сутры через призму даосского или конфуцианского сознания при поиске аналогичных по содержанию и смыслу понятий из привычной терминологической системы. 
Неслучайно Л. Е. Янгутов подчеркивает стремление к некой стандартизации, в результате чего на основе хорошо усвоенного старого получались приращенные знания: «Метод гэ $u$ - это метод понимания буддийских текстов через традиционные китайские идеи, метод сознательного поиска схожих черт между буддийскими и китайскими учениями, использование традиционных терминов и понятий для перевода буддийских. Но это не механическое использование китайской терминологии, а целенаправленный поиск эквивалентов буддийским понятиям и идеям. Это выработка определенных стандартов применения этих эквивалентов при передаче содержания буддийских текстов. Уже в самом названии отражена суть метода: "гэ" переводится как "норма", "стандарт"; "и" — как "смысл", "значение", "гэ и", таким образом, можно перевести как метод "стандартизированного смысла" или как метод приведения смысла (значения) к определенному стандарту. Этот стандарт - среднее между китайским и буддийским содержанием переводимых текстов. В его основе лежит принцип усвоения нового знания на базе хорошо усвоенного старого. Поэтому метод гэ-и по сути своей представлял собой не столько метод перевода буддийских текстов с использованием даосской терминологии, как об этом часто пишут, сколько метод постижения этих текстов на базе традиционного китайского (в первую очередь - даосского) мировосприятия» $[9$, c. 40].

Отсюда и качественно новое эвристическое знание - китайский буддизм с местной спецификой. Древние китайские переводчики уже тогда столкнулись с герменевтической проблемой разных культурно-исторических традиций, личностного фактора и сознания самого интерпретатора с его предрассудками и предмнениями. В процессе перевода осуществлялось предварительное знакомство с индийским буддизмом, а дальнейшая работа с новым смыслом свидетельствовала не о точном воспроизведении истинного значения, а приоритете интерпретации в ином культурном контексте.

Как и любой текст, буддийские сутры несли определенный смысл, значит нуждались в детальной интерпретации. Сложностей в процессе перевода сутр было много, в том числе совершенно разная природа китайского языка и санскрита, недостаточная информация об Индии и функционировании буддизма в стране оригинала, почти полное отсутствие квалифицированных переводчиков со знанием сразу двух языков. И поэтому на раннем этапе это была группа переводчиков-монахов с обязательным присутствием иностранного монаха. Смысл оригинального текста всегда ускользал, несмотря на коллективные усилия. Тем не менее метод гэ $u$ выполнил свою историческую роль на этапе первых попыток распространения буддийской литературы в народе.

Несомненно, здесь имел место своеобразный когнитивный процесс — истолкование содержания от одного слова или словосочетаний к другому слову, для этого подбирались и использовались семантические соответствия из числа терминов китайской философии. В акте познания переводчики-монахи сперва осуществляли для себя объяснение смысла, потому что они изначально занимали подчиненную позицию по отношению к учению Будды. Если бы первые переводчики не прибегли к помощи даосской терминологии, им бы не удалось сделать грандиозный вклад в процесс распространения и адаптации буддизма в Китае. 
И. С. Болдонова, Чжао Чуньмэй. Герменевтический аспект интерпретации буддийских текстов методом гэ $u$

В процессе истолкования они шаг за шагом шли от гипотезы к ее проверке и поиску аналогии, осуществляя своего рода гносеологическую деятельность, используя уже имеющийся базис даосизма. Многие исследователи подчеркивают несовершенство метода гэ $u$, но такая интерпретация была исторически и культурно оправдана, она пошла по пути наименьшего сопротивления в чуждом контексте, в окружении недоверчивых людей китайского общества.

«Самой главной трудностью, с которой столкнулись первые переводчики, пишет А. В. Чебунин, - являлось коренное отличие китайского языка от санскрита, что затрудняло фонетическую передачу как имен, так и базовых понятий, отсутствующих в китайской духовной культуре. В итоге одна часть понятий начинает транскрибироваться, а другая - заменяться китайскими понятиями, передающими основной смысл. В первом случае это были незаменимые имена или термины, наподобие Будда (фото, 佛陀), шрамана (шамэнь, 沙门), архат (алохань, 阿 罗汉), анагамин (анахань, 阿那含), сакритагамин(сытохань, 斯陀含), сротопанна (сюйтохуань, 须陀洹) и т. д. Причем специфика иероглифической письменности позволяла записывать похожие и одни и те же звуки через разные иероглифы, в результате одно слово могло быть записано различным способом. Например, имя Будда записывалось как сюту (休屠), футо (浮陀), футу (浮图), футоу (浮头), бото (勃陀), бодо (勃驮), буто (部陀), муто (母陀), модо (没驮) и т. д. Наряду с этим использовались и переводы имени Будды, такие как Пробужденный (цзюечжэ, 觉 者) и Мудрец (чжичжэ, 智者). Разные переводчики использовали различные варианты, особенно если не знали переводов предшественников. Подобные расхождения существовали длительный исторический период до определенной унификации, проведенной известными переводчиками. Однако на начальном этапе об унификации понятий говорить не приходилось. Во втором случае отсутствие базовых буддийских понятий в китайской духовной культуре, приводившее к полному непониманию их смысла, обусловливало подбор китайских терминов, более или менее соответствующих по содержанию» [8, с. 27-28].

Безусловно, трудно было требовать полноценного грамматического и филологического анализа от переводчиков-монахов того времени, но совместная работа с иностранными монахами все равно позволяла им в какой-то степени выявлять сакральные смыслы. Говоря герменевтическим языком, они не могли обойтись без историко-культурной интерпретации. И подбор семантических аналогий, использование кальки или транскрипции позволяли первым интерпретаторам пропустить содержание сначала через себя и свое понимание, тем самым выявить и определить отношение сознания китайских монахов к сутрам. Само содержание буддийских текстов, отражающих учение Будды, давало возможность всем тем, кто соприкоснулся к этим идеям, переосмыслить не только свою родную языковую картину мира, но и свое отношение к бытию, изменить самосознание. Сама переводческая деятельность давала возможность монахам приобщиться к оригиналу Дхармы и тем самым осознать путь освобождения, приобщения к истине, которую проповедовал Будда.

Г.-Г. Гадамер добавляет к классическим герменевтическим процедурам интерпретации, понимания еще и аппликацию (применение), так что герменевтиче- 
ский процесс складывается из трех сторон: истолкование или интерпретация результируется в понимании, что, в свою очередь, находит выход в применении или аппликации. Категория аппликации в теории Г.-Г. Гадамера означает действительное понимание самого всеобщего, воплощением чего в конкретном и единичном виде является анализируемый опыт [1]. В методе гэ $и$ гадамеровская категория аппликации была реализована не только индивидуальным духовным развитием переводчиков и их содержательным опытом, но и всем последующим историческим развитием буддизма в Китае. В данном случае можно догадываться о первоначальной и примитивной форме робкого диалога со священными текстами, в результате чего и получился новый качественный продукт - китайский буддизм.

В самой Индии, на родине буддизма, широко применялась так называемая буддийская герменевтика, методология, которая выработала свои определенные принципы и правила интерпретации и понимания священных текстов буддизма. Буддийская герменевтика сформировалась в условиях использования разной терминологии многими направлениями и школами буддизма, и чтобы понять друг друга и не отходить от учения Будды, им необходимо было выработать общий методологический подход к интерпретации текстов.

Буддийская герменевтика несколько по-другому решала проблему понимания, где главным принципом интерпретации была как можно полная близость к истине или подлинности слов Будды. На основе этого принципа были сформулированы четыре основных правила:

«1. Опирайся на Учение (Дхарма), а не на личность (пудгала) учителя; 2. Опирайся на цель (артха) и смысл текста, а не на его букву; 3 . Опирайся на прямое (нитартха) значение, а не на (неяртха) истолкование; 4. Опирайся на интуитивноочевидное (джняна), а не на дискурсивное (виджняна) знание» [3, с. 9]. Как видно их этих правил, личностный фактор интерпретатора совсем не учитывался, в связи с этим даже видимость диалога здесь полностью отсутствовала. В данном случае разница культурных традиций и сознаний не является препятствием правильной интерпретации, главным критерием является следование Дхарме. Поэтому немаловажным элементом сутр становится убедительное доказательство того, кем была произнесена проповедь и кто присутствовал при этом. Герменевтический аспект индийской буддийской герменевтики указывает на важность прямого семантического, а не переносного значения, что имеет очевидную ценность в многочисленных комментариях. В противном случае в данном обстоятельстве скрывается опасность далеко уйти от первоначального значения. И наоборот, привлечение дискурсивных знаний не являлось большой необходимостью в интерпретациях внутри Индии, даже при наличии большого количества направлений и школ. Но в этих правилах также допускается некоторая возможность использования интуиции и эмпатии, что, в свою очередь, не противоречит строгому подчинению правилам интерпретации, выявлению истины и приближению подлинному понимаю Дхармы.

Герменевтический аспект в индийской буддийской герменевтике появляется в учете особенностей восприятия аудиторией, о чем указывается во втором правиле - опирайся на цель текста.

По мнению С. Ю. Лепехова, А. М. Донца, С. П. Нестеркина, «Буддийское учение с самого начала имело герменевтическую направленность, поскольку 
И. С. Болдонова, Чжао Чуньмэй. Герменевтический аспект интерпретации буддийских текстов методом гэ $u$

Будда не претендовал на абсолютную истинность своих проповедей. Абсолютной истинностью обладала Дхарма, которой следовал и которой учил Будда, но которая не могла быть полностью адекватно выражена в словах. Далее в силу того, что проповедь адресовалась разным людям, с различным уровнем сознания, одно и то же содержание необходимо было выражать разными способами» [3, с. 8]. В данном случае имеется противоречие, которое заключается, с одной стороны, во вспомогательной роли сознания интерпретатора, с другой - в необходимости включения его же сознания и личностных факторов в адаптацию и интерпретацию текста для разных категорий людей и жизненных ситуаций, но это обстоятельство не мешает следовать строгим канонам поиска истинного смысла текста.

С целью текста и ориентацией на восприятие аудитории тесно связано практическое применение результатов понимания текстов. Стоит отметить роль и значение герменевтической категории аппликации (применение) в последующем функционировании усвоенного смысла. С. Ю. Лепехов, А. М. Донец, С. П. Нестеркин указывают на аппликацию или применение в виде изменений психического состояния, поведения личности и соответствующих ритуальных действий, и поэтому авторы неслучайно называют такое применение «экзистенциальным комментарием» [3, с. 16]. Глубина постижения истины находила отражение в степени поглощенности смыслом и самоотдаче в реализации новых жизненных установок.

Некоторое сравнение с буддийской герменевтикой в самой Индии дает возможность рассмотреть интерпретацию метода гэ $u$ с позиции «родная среда / неродная среда». Китайские переводчики-монахи должны были опираться не только на личность иностранного монаха, носителя индийской культуры и санскрита, но и на собственный лингвистический и гносеологический потенциал. Смысл текста не всегда поддавался правильному пониманию по ряду известных причин, и тогда вступали в силу дискурсивные знания, имеющиеся в китайской культуре, автохтонных религиях и межкультурной коммуникации. Китайские переводчики уже в древности научились использовать общеизвестные приемы перевода, они применяли калькирование или транскрипцию в контексте китайского языка и санскрита, ими использовались даосские термины по аналогии и парные числовые списки терминов как способ формализации мышления. В. И. Рудой приводит следующие примеры: «Например, махабхута ("четыре великих [элемента] ") приравнивалась к китайским "пяти элементам" (у-син), а панча шила - "пять обетов", обязательных для буддиста-мирянина, - к у-чан — "пяти постоянствам", нормативным конфуцианским добродетелям» [4]. Все эти приемы свидетельствуют о специфическом подходе к интерпретации буддийских сутр в ситуации полной недоступности оригинального смысла. Интерпретативное знание имело положительный результат на раннем этапе переводов, но в конечном итоге привело к путанице и неопределенности в толковании текстов. Стремление метода гэ $и$ к стандарту привело к обратному результату, в связи с чем переводчики вынуждены были отказаться от этого метода.

Несмотря на известное несовершенство, метод гэ $u$ стал своеобразным мостом между двумя культурами и религиями. Переведенные и отредактированные тексты стали формой сообщения в межкультурной коммуникации между китайской и индийской культурами. Эти переводы сразу же превратились в источники 
новых знаний и нововведений, потому что они уже вышли из-под пера переводчика, попали в межкультурный контекст, в смысловом аспекте стали создавать некое символическое поле смыслов взаимодействия буддизма и китайских религиозно-философских учений.

В области социального поведения адаптированные к китайскому способу восприятия переведенные сутры структурно модифицировали этически-ритуальный комплекс местных религий, но в конечном итоге индийский буддизм сам больше потерял свою специфику, не устояв в функциональном аспекте перед более мощной китайской культурой. И далее буддизм обрел институциональный статус в результате перевода и межкультурного диалога, благодаря распространению буддизма появились новые коды поведения, культурные символические смыслы.

На метатеоретическом уровне метод гэ $u$ в широком значении открывает для китайского традиционного сознания возможности дальнейшего межкультурного диалога между Западом и Востоком. В методе гэ $u$ гармоничным образом соединились проблемы перевода, проблемы интерпретации, герменевтические аспекты взаимодействия в межкультурном диалоге, и, конечно же, проблема понимания. Данная проблема шире проблемы самого метода, потому что она определяет наше бытие. Понимание в любой методологии во все времена и в любом конкретном пространстве всегда волновала людей как общекультурная, общечеловеческая фундаментальная проблема, от которой зависит наше существование.

Исследование выполнено при финансовой поддержке Государственного фонда социальных наук Китая в рамках научно-исследовательского проекта «Переводы достижений китайских ученых на иностранные языки» 2019 г., перевода книги «История Китая в кратком изложении», № $19 \mathrm{WZSB013.}$

\section{Литература}

1. Гадамер Г.-Г. Истина и метод: Основы философской герменевтики. М.: Прогресс, 1988. 699 c.

2. Костикова О. И., Чжэнь Шуи. Становление китайской переводческой традиции: практика, критика, теория // Вестник Московского университета. Сер. 22. Теория перевода. 2012. № 1. C. 31-48.

3. Лепехов С. Ю., Донец А. М., Нестеркин С. П. Герменевтика буддизма. Улан-Удэ: Изд-во БНЦСО РАН, 2006. 264 с.

4. Рудой В. И. Введение в буддизм. СПб.: Лань. URL: https://webshus.ru/19393 (дата обращения: 04.04.2020).

5. Тан Юнтун. О Гэ и - самом раннем средстве слияния индийского буддизма и китайской философии // Неоконфуцианство, буддизм и даосизм. Пекин: Изд-во Пекин. унTa, 1991. C. 282-284. 汤用粀, "论格义--最早一种融合印度佛教和中国思想的方法"(发表 于 1948 年), 载于:汤用䑣, 《理学、佛学、玄学》, 北京, 1991 年, 第 282-284 页

6. Фэн Ю-лань. Вновь составленная история китайской философии. Пекин: Народное изд-во, 1992. Т. 4. С. 213-214. 冯友兰, 《中国哲学史新编》, 第四册, 人民出版社, 北京，1992 年, 第 213-214 页

7. Фэн Ю Лань Краткая история китайской философии. М.: Евразия, 1998. 374 с.

8. Чебунин А. В. Начальный период проникновения, распространения и китаизации буддизма в Китае // Вестник Бурятского государственного университета. Философия. 2019. Вып. 2. С. 21-30.। 
И. С. Болдонова, Чжао Чуньмэй. Герменевтический аспект интерпретации буддийских текстов методом гэ $u$

9. Янгутов Л. Е. Традиции Праджняпарамиты в Китае. Улан-Удэ: Изд-во Бурят. гос. ун-та, 2007. 272 с.

\section{HERMENEUTIC ASPECT OF BUDDHIST TEXTS INTERPRETATION BY THE GEYI METHOD}

\section{Irina S. Boldonova}

Dr. Sci. (Philos.), A/Prof., Visiting Prof. of Russian Language Department of Nankai University (China), Prof. of Russian and Foreign Literature Department

Dorzhi Banzarov Buryat State University,

24a Smolina St., Ulan-Ude 670000, Russia

E-mail: irina_duncan@mail.ru

\section{Zhao Chunmei}

Ph.D., A/Prof. of Russian Language Department, Nankai University Foregn Languages Institute

94 Weijinlu St., Tianjin 300371, China

E-mail : 1559614118@qq.com

The article deals with the geyi method, which Taoist monks used for interpretation of Buddhist sutras during the spread of Buddhism from India to China. It is emphasized the cultural and historical role of the geyi method at the early stage of Indian Buddhism penetration into China and its specific way of interpretation by matching Sanskrit terminology by similar terms and concepts of Chinese philosophy. We consider the hermeneutic aspect of the geyi method through such categories as interpreter's consciousness, the process of cognition, cultural and historical tradition, intercultural communication, application, and the problem of understanding. The article also compares the interpretation by the geyi method with the same process in Buddhist hermeneutics, and this help us to identify the features of the hermeneutic aspect in the geyi method. Each method solves in its own way the problems of truth, understanding and interpretation of the sacred texts. Finally, we come to the conclusion about the heuristic significance of the geyi method and its essential role in the development of intercultural communication.

Keywords: the geyi method; Buddhism; Chinese philosophy; hermeneutic aspect; Buddhist texts; Taoist monks-interpreters; interpretation; understanding; cultural and historical tradition; Buddhist hermeneutics. 